NOTE

\title{
Azumiobodo hoyamushi, the kinetoplastid causing soft tunic syndrome in ascidians, may invade through the siphon wall
}

\author{
Euichi Hirose $^{1, *}$, Akira Kumagai ${ }^{2}$, Akatsuki Nawata ${ }^{3}$, Shin-Ichi Kitamura ${ }^{4,5}$ \\ ${ }^{1}$ Department of Chemistry, Biology and Marine Science, Faculty of Science, University of the Ryukyus, Nishihara, \\ Okinawa 903-0213, Japan \\ ${ }^{2}$ Miyagi Prefecture Fisheries Technology Institute Freshwater Fisheries, Experimental Station, Taiwa, Miyagi 981-3625, Japan \\ ${ }^{3}$ Miyagi Prefecture Fisheries Technology Institute, Ishinomaki, Miyagi 986-2135, Japan \\ ${ }^{4}$ Department of Biology, Faculty of Science, Ehime University, Matsuyama, Ehime 790-8577, Japan \\ ${ }^{5}$ Center for Marine Environmental Studies (CMES), Ehime University, Matsuyama, Ehime 790-8577, Japan
}

\begin{abstract}
The infectious kinetoplastid Azumiobodo hoyamushi causes 'soft tunic syndrome', a serious problem in aquaculture of the edible ascidian Halocynthia roretzi. Infection tests using diseased tunics demonstrated that juvenile $(0.8 \mathrm{yr}$ old $)$ individuals never developed soft tunic syndrome, but all individuals in the other age groups $(1.8,2.8$, and $3.8 \mathrm{yr}$ old $)$ showed the disease symptoms. In the infection tests, tunic softening was first observed at the tunic around siphons. Based on ultrastructural observation of the inner wall of the branchial siphon, the tunic lining the inner wall in juveniles ( $0.5 \mathrm{yr}$ old) was completely covered with cuticle, which had a dense structure to prevent bacterial and protist invasion. In contrast, the tunic was often partly damaged and not covered with cuticle in healthy adults ( $\geq 2.5 \mathrm{yr}$ old). The damaged tunic in the siphon wall could be an entrance for $A$. hoyamushi into the tunic of adult hosts.
\end{abstract}

KEY WORDS: Halocynthia roretzi - Edible ascidian - Aquaculture - Age-dependent susceptibility · Tissue damage $\cdot$ Tunic cuticle $\cdot$ Ultrastructure

\section{INTRODUCTION}

Soft tunic syndrome is an infectious disease of the edible ascidian Halocynthia roretzi, causing mass mortality in aquaculture in Korea and Japan (e.g. Jung et al. 2001). The pathogen, Azumiobodo hoyamushi, is a kinetoplastid and fulfills Koch's postulates as the etiological agent (Kumagai et al. 2010, 2011, Hirose et al. 2012). Although the farming facilities in Miyagi and Iwate Prefecture, Japan, were completely destroyed by the tsunami caused by the Tohoku Region Pacific Coast Earthquake in 2011, A. hoyamushi was detected in wild populations of ascidians after the tsunami (Kumagai et al. 2013). There- fore, the disease is a potential threat to the reconstruction of ascidian aquaculture in Japan, and outbreaks continue to be a problem in Korea. However, many aspects of the infection remain unclear.

In diseased ascidians, A. hoyamushi is exclusively found in the softened tunic (Kumagai et al. 2010, 2011). Where is the entrance for the kinetoplastids into the tunic? It would be difficult to invade the ascidian tunic from the tunic surface because the cuticle covering the tunic matrix has a dense structure and can prevent microorganisms from invading (reviewed in Burighel \& Cloney 1997). Healthy individuals of $H$. roretzi possess a tough tunic covered with thick cuticle, whereas the cuticle is thinner in 
diseased individuals (Hirose et al. 2009, Kitamura et al. 2010). The tunic entirely covers the epidermis, and only the edges of the tunic are present at the junction of epidermis and siphon epithelium (epithelium lining the inner wall of siphons) (e.g. Buencuerpo 1988). Interestingly, we found that tunic softening first occurred around the siphons in the infection tests (Kumagai et al. 2010), suggesting that this region is the pathogen entry site. On the other hand, only adults develop soft tunic syndrome, while juveniles appear healthy in the same farming facilities (Kumagai et al. 2010). The difference in susceptibility between juveniles and adults is inconsistent with the fact that the tunic cuticle of adults is much thicker than that of juveniles.

In the present study, we confirmed that juveniles did not become infected with $A$. hoyamushi, whereas adults showed the disease symptoms under the same experimental conditions. We compared ultrastructures of the tunic lining the inner wall of the branchial siphon between juveniles and adults to determine the entry site of the infectious kinetoplastids.

\section{MATERIALS AND METHODS}

\section{Infection test}

Healthy Halocynthia roretzi were collected from a farming site where the disease was not present. Their approximate ages (based on the date of the natural spat collection) were $0.8,1.8,2.8$, and $3.8 \mathrm{yr}$ old (see Kumagai et al. 2010). The tunics of diseased individuals (2.5 yr old, $\mathrm{n}=5$ ) were cut into pieces (ca. $5 \times$ $1 \mathrm{~cm}, 80 \mathrm{~g}$ in total). The tunics pieces of $20 \mathrm{~g}$ each were put into a polyethylene net (mesh size $7.5 \times$ $7.5 \mathrm{~mm}$ ) and suspended in a $25 \mathrm{l}$ aquarium containing healthy individuals ( $\mathrm{n}=12$ to 44 ). The aquarium was supplied with running seawater $\left(13\right.$ to $\left.17^{\circ} \mathrm{C}\right)$. For a control experiment, tunic pieces $(20 \mathrm{~g})$ from healthy $2.8 \mathrm{yr}$ old individuals were suspended in another aquarium. The ascidians were reared for $50 \mathrm{~d}$ without feeding, and the number of individuals showing disease symptoms was recorded.

\section{Microscopy}

Healthy juveniles ( $0.5 \mathrm{yr}$ old) and adults (2.5 yr old or older) were respectively collected from a farming site and a natural habitat where the disease had not occurred. The age of juveniles was determined based on the date of the spat collection and those of adults were estimated based on their sizes. The juveniles were fixed in $2.5 \%$ glutaraldehyde, $0.45 \mathrm{M}$ sucrose and $0.1 \mathrm{M}$ sodium cacodylate at $\mathrm{pH}$ 7.4. The branchial siphons cut from adults were fixed in the same fixative. The fixed specimens were rinsed with $0.1 \mathrm{M}$ cacodylate-0.45 $\mathrm{M}$ sucrose, and post-fixed for $1.5 \mathrm{~h}$ in $1 \%$ osmium tetroxide-0.1 M cacodylate. Then the specimens were dehydrated with ethanol, cleared with $n$-butyl glycidyl ether, and embedded in epoxy resin. Sections were made from 3 juvenile and 4 adult specimens: thick sections were stained with toluidine blue for light microscopy and thin sections were stained with uranyl acetate and lead citrate for transmission electron microscopy using JEM-1011 (JEOL).

\section{RESULTS}

\section{Susceptibility among age groups}

None of the juvenile (0.8 yr old) individuals developed soft tunic syndrome, but all individuals of the other age groups (i.e. 1.8, 2.8, and 3.8 yr old) showed the disease symptoms within $38 \mathrm{~d}$ (Table 1). Tunic softening was first observed at the tunic around siphons.

\section{Fine structures of the inner wall of the branchial siphon}

Adults. Fig. 1A-C shows the gross morphology of the apical part of the branchial siphon. The epidermis covering the body bent at the rim of the siphon onto the inner side of the siphon, and became continuous with the epithelium lining the inner wall of the

Table 1. Susceptibility to the infectious kinetoplastid Azumiobodo hoyamushi among age groups of the ascidian Halocynthia roretzi

\begin{tabular}{|lccc|}
\hline $\begin{array}{l}\text { Tunic pieces } \\
\text { incubated } \\
\text { with ascidians }\end{array}$ & $\begin{array}{c}\text { Age group } \\
\text { (yr old) }\end{array}$ & $\begin{array}{c}\text { No. of } \\
\text { ind. }\end{array}$ & $\begin{array}{c}\text { No. of } \\
\text { diseased } \\
\text { ind. (\%) }\end{array}$ \\
\hline $\begin{array}{l}\text { Softened tunic } \\
\text { (diseased) }\end{array}$ & 0.8 & 44 & $0(0)$ \\
& 1.8 & 20 & $20(100)$ \\
& 2.8 & 12 & $12(100)$ \\
Healthy tunic & 3.8 & 12 & $12(100)$ \\
(control) & 0.8 & 78 & $0(0)$ \\
& 1.8 & 20 & $0(0)$ \\
& 2.8 & 12 & $0(0)$ \\
& 3.8 & 12 & $0(0)$ \\
\hline
\end{tabular}



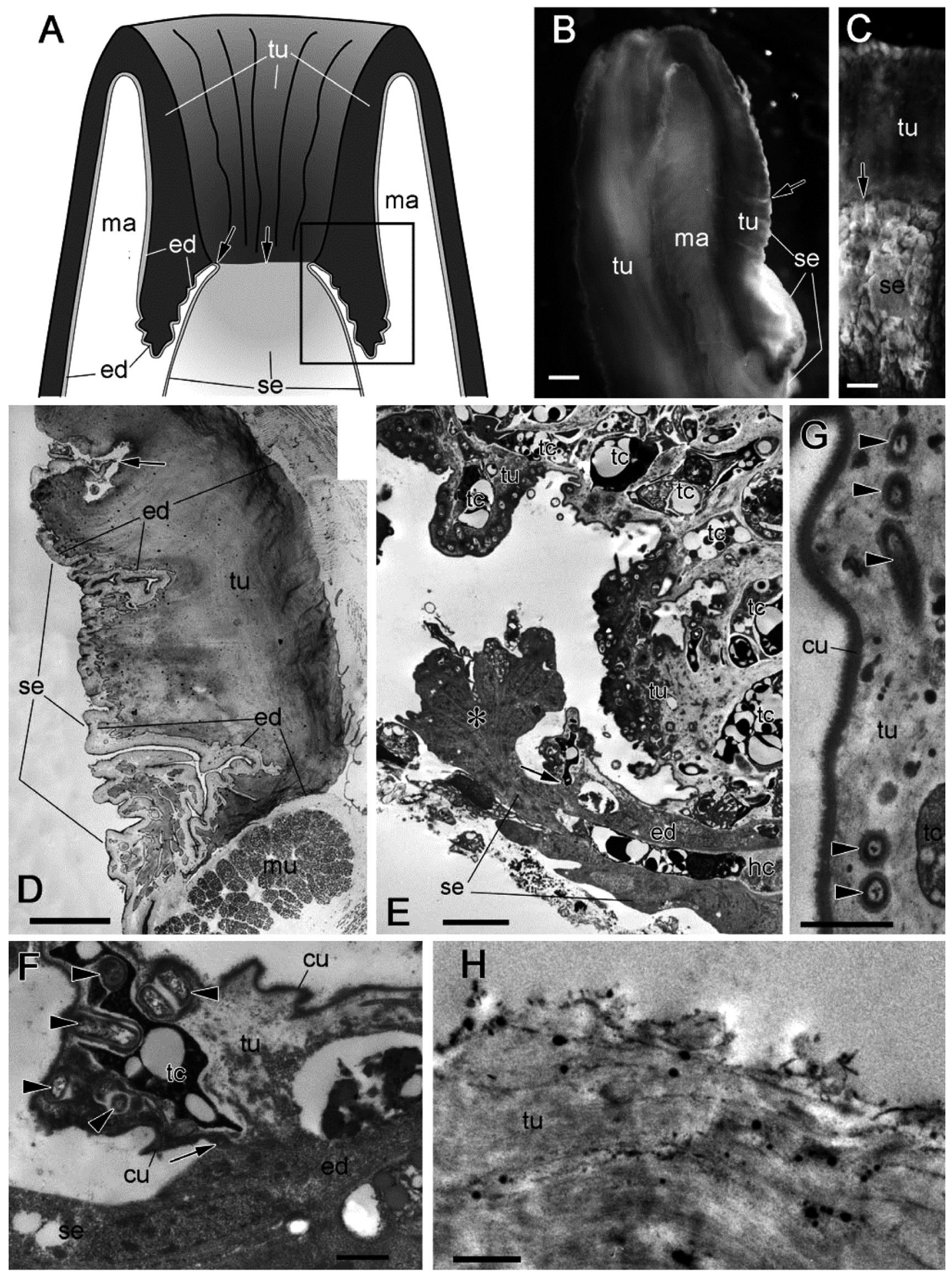

Fig. 1. Adult Halocynthia roretzi (2.5 yr old or older). (A) Schematic drawing of the branchial siphon. The rectangle is the approximate area shown in (D). (B) Section of the siphon wall (lumen at right). (C) Inner wall surface. (D) Histological section of the inner wall. (E-H) Transmission electron microscopy. (E) Junction of the epidermis and siphon epithelium; the asterisk denotes the fold of siphon epithelium forming a cellular lip at the velum rim. (F) Enlargement of the junction (edge of tunic cuticle appears to contact the epidermal cell). (G) Tunic on the inner wall covered with tunic cuticle. (H) Tunic on the inner wall without tunic cuticle (fibrous tunic matrix is exposed to the siphon lumen). Arrows indicate the edge of tunic; arrowheads show bacterial cells. $\mathrm{cu}$, tunic cuticle; ed, epidermis; hc, hemocoel; ma, mantle in the siphon wall; mu, circular muscle in the mantle; se, siphon epithelium; tc, tunic cell; tu, tunic. Scale bars: (B-C) $1 \mathrm{~mm},(\mathrm{D}) 0.2 \mathrm{~mm},(\mathrm{E}) 5 \mu \mathrm{m},(\mathrm{F}-\mathrm{H}) 1 \mu \mathrm{m}$ 
siphon, which is referred to as siphon epithelium in this article. The tunic entirely covered the epidermis and ended at the junction between the epidermis and the siphon epithelium (arrows in Fig. 1). The junction formed a horizontal line approx. $5 \mathrm{~mm}$ from the rim of the siphon (Fig. 1A,C). In histological sections, the circular muscles were well-developed in the siphon mantle (Fig. 1D). The siphon epithelium made a fold that formed the cellular lip at the velum rim. The siphon epithelium and epidermis were joined near the lip (Fig. 1E). Many tunic cells were distributed in the tunic matrix. The tunic ended at the junction, and the edge of the tunic cuticle appeared to contact the epidermal cell membrane; there was no gap sufficient for microorganisms to invade the tunic (Fig. 1F). Nevertheless, bacterial cells were found in the tunic around the junction in all adult specimens (arrowheads in Fig. 1F,G). Some parts of the tunic were not covered with cuticle, and fibrous tunic matrix was exposed in all specimens examined (Fig. 1H).

Juveniles. Juveniles were only a few millimeters in length, and the siphons were 0.3 to $0.4 \mathrm{~mm}$ in diameter (Fig. 2A). The tunic entirely covered the epidermis and joined with the siphon epithelium at the velum rim on the inner wall of the siphon (Fig. 2B,C). The tunic ended at the junction; the edge of the tunic cuticle appeared to contact the epidermal cell membrane (Fig. 2D). The cuticle surface was covered with minute protrusions of about $0.1 \mu \mathrm{m}$ in height (arrowheads in Fig. 2E). Tunic cuticle was always overlaid on the tunic (Fig. 2F), and no bacterial cells were found in the tunic matrix of any specimens examined.

\section{DISCUSSION}

Infection tests confirmed that the juveniles did not become infected with Azumiobodo hoyamushi, while the adults showed the disease symptoms under the same experimental conditions. This result suggests that there are differences in structures and physiology associated with infection between adults and juveniles. In experimental infection, tunic softening was first observed on the tunic around siphons (Kumagai et al. 2010), and thus we focused on structures of the inner wall of branchial siphons (particularly on the edge of the tunic) in healthy juveniles and adults.

The gross structure of the inner wall of branchial siphons was the same in juvenile and adults: the epidermis covered with tunic reached the siphon epithelium at the velum rim, and the tunic ended at the junction between the 2 cellular sheets. There was no gap between the edge of the cuticle and the epidermal cell; hence, pathogens cannot enter the tunic via this route. Unexpectedly, many bacteria were distributed in the tunic around the junction in adult specimens; bacterial cells were rarely found in the tunic covering the body mantle in healthy adults (Hirose et al. 2009). In contrast to the adults, there were no bacteria in the tunic of juvenile specimens. In adult specimens, tunic cuticle did not cover the tunic matrix in some parts of the tunic lining the inner wall of the siphon. This could function as an entrance not only for bacteria but also for A. hoyamushi into the tunic matrix. The adults examined in this study were healthy and showed no symptoms of the disease, but they had damage on the inner tunic wall of the siphon. In juvenile specimens, the tunic of the inner wall was completely covered with tunic cuticle, which is a dense structure able to prevent bacterial and protist invasion. Accordingly, the difference in susceptibility to $A$. hoyamushi between juveniles and adults could be explained by the presence or absence of damaged tunic on the inner wall of the siphon. This is probably the major site for infection in adult $H$. roretzi, which explains why the tunic is softened first around the siphon.

It is unclear why the inner wall tunic is often damaged in adults. Whereas the tunic on the body mantle always has a thick cuticle layer in adults, the thickness is quite variable (Hirose et al. 2009). The siphons are elastic organs that open and close the apertures, and muscles are well developed in the mantle of the siphon in both adults and juveniles. Therefore, the tunic cuticle of the inner tunic wall is probably thin to retain elasticity. When the siphon contracts the circular muscles to tightly close the aperture, the tunics lining the inner wall of the siphon rub strongly against each other. Due to this action, the tunic cuticle layers likely become damaged. In juveniles, the entire tunic is thinner and more elastic than adults, and the force required to close its small aperture should be much lower than in adults. Accordingly, the tunics lining the inner wall would not be as damaged.

In adult specimens, many tunic cells (as well as bacterial cells) were distributed in the tunic around the junction between epidermis and siphon epithelium. Ascidians usually contain several types of tunic cells that have various roles in the tunic (reviewed in Hirose 2009). Among 6 types of tunic cells described from $H$. roretzi (Hirose et al. 2009), many tunic cells observed here were vacuolated tunic cells and tunic phagocytes. They may have gathered in the tunic, responding to the bacterial infection. Tunic phago- 

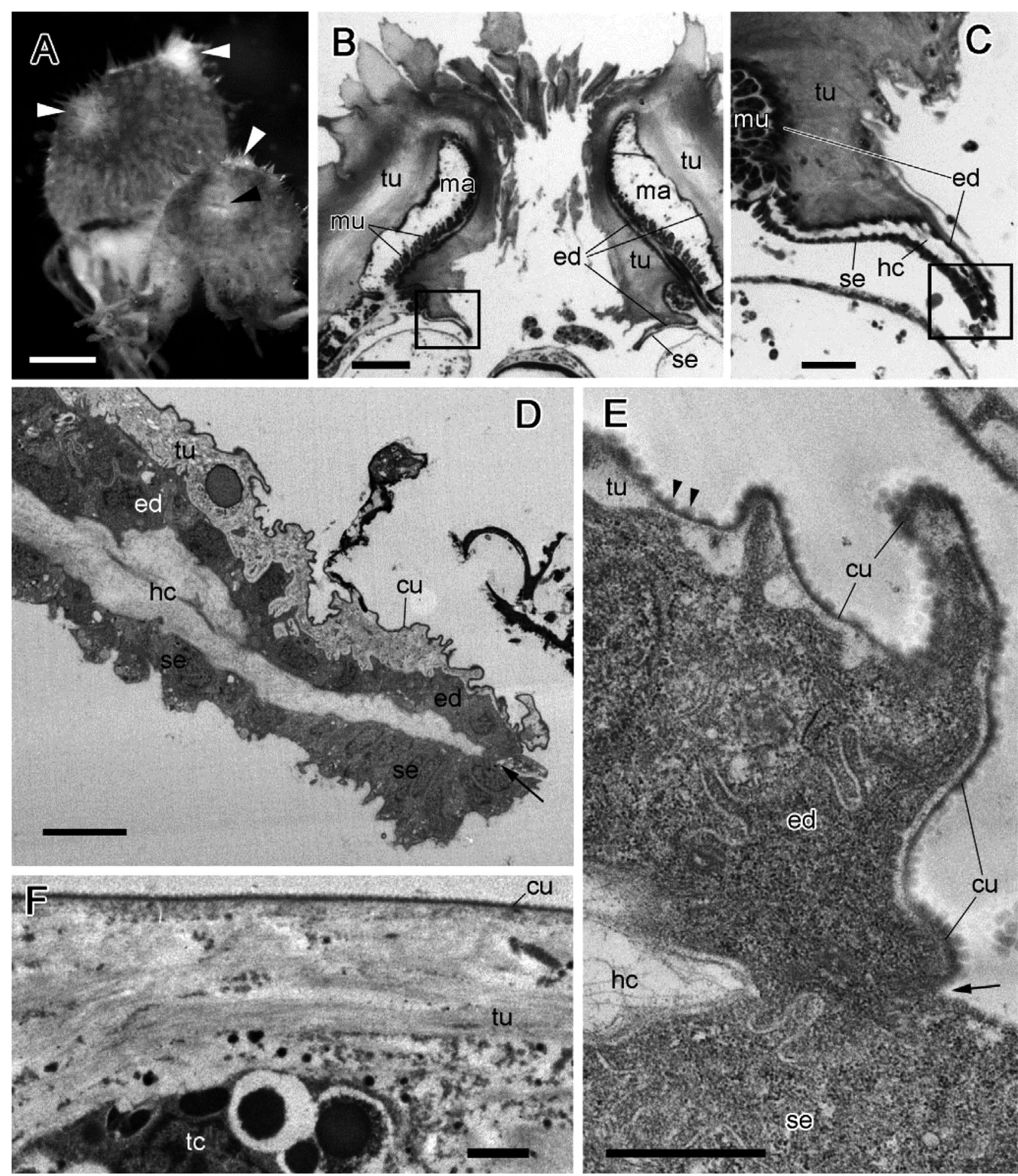

Fig. 2. Juvenile Halocynthia roretzi (0.5 yr old). (A) Two individuals are shown; each has 2 siphons (arrowheads). (B) Histological section of branchial siphon. The rectangle in (B) is the approximate area shown in (C). (C) Histological section of velum where the epidermis and siphon epithelium join. The rectangle in (C) is the approximate area shown in (D). (D-F) Transmission electron micrographs. (D) Junction of epidermis and siphon epithelium. (E) Enlargement of the junction (edge of tunic cuticle appears to contact the epidermal cell; arrowheads indicate minute protrusions covering the cuticle surface). (F) Tunic on the inner wall. No bacterial cells were found. Arrows indicate the edge of tunic. cu, tunic cuticle; ed, epidermis; hc, hemocoel; ma, mantle in the siphon wall; mu, circular muscle in the mantle; se, siphon epithelium; tc, tunic cell; tu, tunic. Scale bars $=(A) 1 \mathrm{~mm}$, (B) $0.1 \mathrm{~mm}$, (C) $20 \mu \mathrm{m}$, (D) $5 \mu \mathrm{m},(\mathrm{E}-\mathrm{F}) 1 \mu \mathrm{m}$ 
cytes may endocytose the bacteria, while the functions of vacuolated tunic cells remain unclear.

In Korea, mass mortality of Halocynthia roretzi due to soft tunic syndrome has been a serious problem since 1995 (Jung et al. 2001). The first record of this disease in Japan was in 2007 from farming facilities where Korean spat had been introduced (Kumagai et al. 2011). After that time, the infected area gradually expanded from the site where Korean spat was introduced until the tsunami destroyed all farming facilities in Miyagi and Iwate Prefectures in 2011. The progress of the disease outbreak suggests that A. hoyamushi was probably introduced to Japan through the Korean spat, although the present results indicate that juveniles are not susceptible to A. hoyamushi. It is possible that the spat of $H$. roretzi is not the direct carrier of the pathogens, and A. hoyamushi may reside in the materials on which spat attaches as a resting phase, such as a cyst. Jang et al. (2012) reported the cyst-like form of A. hoyamushi in the diseased tunic. It is important to understand the infection process and life cycle of A. hoyamushi to prevent expansion of this infectious disease.

Acknowledgements. This study was supported by KAKENHI (no. 25292119) from the Japan Society for the Promotion of Science to E.H. and S.I.K. and a grant from the Ministry of Agriculture, Forestry, and Fisheries of Japan to A.K.

\section{LITERATURE CITED}

Buencuerpo V (1988) A new description and scanning electron microscope study of the siphons of Dendrodoa grossularia (Tunicata, Ascidiacea). Arch Biol 99:365-376

Burighel P, Cloney R (1997) Urochordata: Ascidiacea. In:

Editorial responsibility: Rebecca Gast, Woods Hole, Massachusetts, USA
Harrison F, Ruppert E (eds) Hemichordata, Chaetognatha, and the invertebrate chordates. Wiley-Liss, New York, NY, p 221-347

> Hirose E (2009) Ascidian tunic cells: morphology and functional diversity of free cells outside the epidermis. Invertebr Biol 128:83-96

> Hirose E, Ohtake SI, Azumi K (2009) Morphological characterization of the tunic in the edible ascidian, Halocynthia roretzi (Drasche), with remarks on 'soft tunic syndrome' in aquaculture. J Fish Dis 32:433-445

- Hirose E, Nozawa A, Kumagai A, Kitamura SI (2012) Azumiobodo hoyamushi gen. nov. et sp. nov. (Euglenozoa, Kinetoplastea, Neobodonida): a pathogenic kinetoplastid causing the soft tunic syndrome in ascidian aquaculture. Dis Aquat Org 97:227-235

Jang HB, Kim YK, del Castillo CS, Nho SW and others (2012) RNA-Seq-based metatranscriptomic and microscopic investigation reveals novel metalloproteases of Neobodo sp. as potential virulence factors for soft tunic syndrome in Halocynthia roretzi. PLoS ONE 7:e52379

Jung SJ, Oh MJ, Date T, Suzuki S (2001) Isolation of marine birnavirus from sea squirts Halocynthia roretzi. In: Sawada H, Yokosawa H, Lambert CC (eds) The biology of ascidians. Springer-Verlag, Tokyo, p 436-441

Kitamura SI, Ohtake SI, Song JY, Jung SJ and others (2010) Tunic morphology and viral surveillance in diseased Korean ascidians: soft tunic syndrome in the edible ascidian, Halocynthia roretzi (Drasche), in aquaculture. J Fish Dis 33:153-160

Kumagai A, Suto A, Ito H, Tanabe T, Takahashi K, Kamaishi T, Miwa S (2010) Mass mortality of cultured ascidians Halocynthia roretzi associated with softening of the tunic and flagellate-like cells. Dis Aquat Org 90:223-234

Kumagai A, Suto A, Ito H, Tanabe T and others (2011) Soft tunic syndrome in the edible ascidian Halocynthia roretzi is caused by a kinetoplastid protist. Dis Aquat Org 95:153-161

Kumagai A, Ito H, Sasaki R (2013) Detection of the kinetoplastid Azumiobodo hoyamushi, the causative agent of soft tunic syndrome, in wild ascidians Halocynthia roretzi. Dis Aquat Org 106:267-271

Submitted: December 23, 2013; Accepted: March 13, 2014 Proofs received from author(s): June 16, 2014 